\title{
ATOMIC NITROGEN DENSITIES NEAR THE POLAR CUSP
}

\author{
M. J. Engebretson and J. T. Nelson \\ Department of Physics \\ Augsburg College \\ Minneapolis, MN 55454
}

The Neutral Atmosphere Composition Spectrometer (NACS) on board the Dynamics Explorer-2 spacecraft sampled several major and minor thermospheric gases including atomic nitrogen. We present here a selection of passes over the polar cusp that provide a quantitative measure of the increase of $\mathrm{N}$ densities due to soft particle precipitation occurring in this region. Increases in $\mathrm{N}$ densities are frequently observed, but are smaller than accompanying increases in $\mathrm{N}_{2}$ densities. Our observations support earlier studies suggesting that 1) $\mathrm{N}$ densities increase more rapidly than $\mathrm{O}$ densities during periods of high solar EUV flux and 2) $\mathrm{N}$ densities are larger in the summer hemisphere than in the winter hemisphere. A series of passes in February 1983, late in the lifetime of DE-2, indicated $\mathrm{N}$ densities at $2000 \mathrm{~km}$ altitude which were a factor of $\approx 2$ larger near the southern cusp than near the northern cusp. 


\section{TABLE I}

Atomic nitrogen denstties in or near the polar cusp late in the lifetime of DE-2.

ORBIT DATE $\quad \mathrm{F}_{10.7} \mathrm{Kp} \quad$ CUSP $\quad$ ALTITUDE $(\mathrm{km}) \quad$ DENSITY $\left(\mathrm{cm}^{-3}\right)$

Northern Hemisphere

$\begin{array}{lllllll}8543 & 83047 & 91.9 & 4 & \mathrm{Y} & 236 & 6.4 \times 10^{6} \\ 8553 & 83048 & 94.2 & 3 & \mathrm{Y} & 238 & 6 \times 10^{6} \\ 8562 & 83048 & 94.2 & 3 & \mathrm{~N} & 186 & 1.1 \times 10^{7}\end{array}$

Southern Hemisphere

$\begin{array}{llcllll}8436 & 83040 & 125.3 & 3+ & \mathrm{Y} & 236 & 1.4 \times 10^{7} \\ 8514 & 83045 & 94.1 & 3 & \mathrm{~N} & 230 & 1 \\ 8551 & 83048 & 94.2 & 4- & \mathrm{Y} & 205 & 2.4 \times 10^{7} \\ 8574 & 83049 & 99 & 3 & \mathrm{~N} & 199 & 2.8 \times 10^{7}\end{array}$




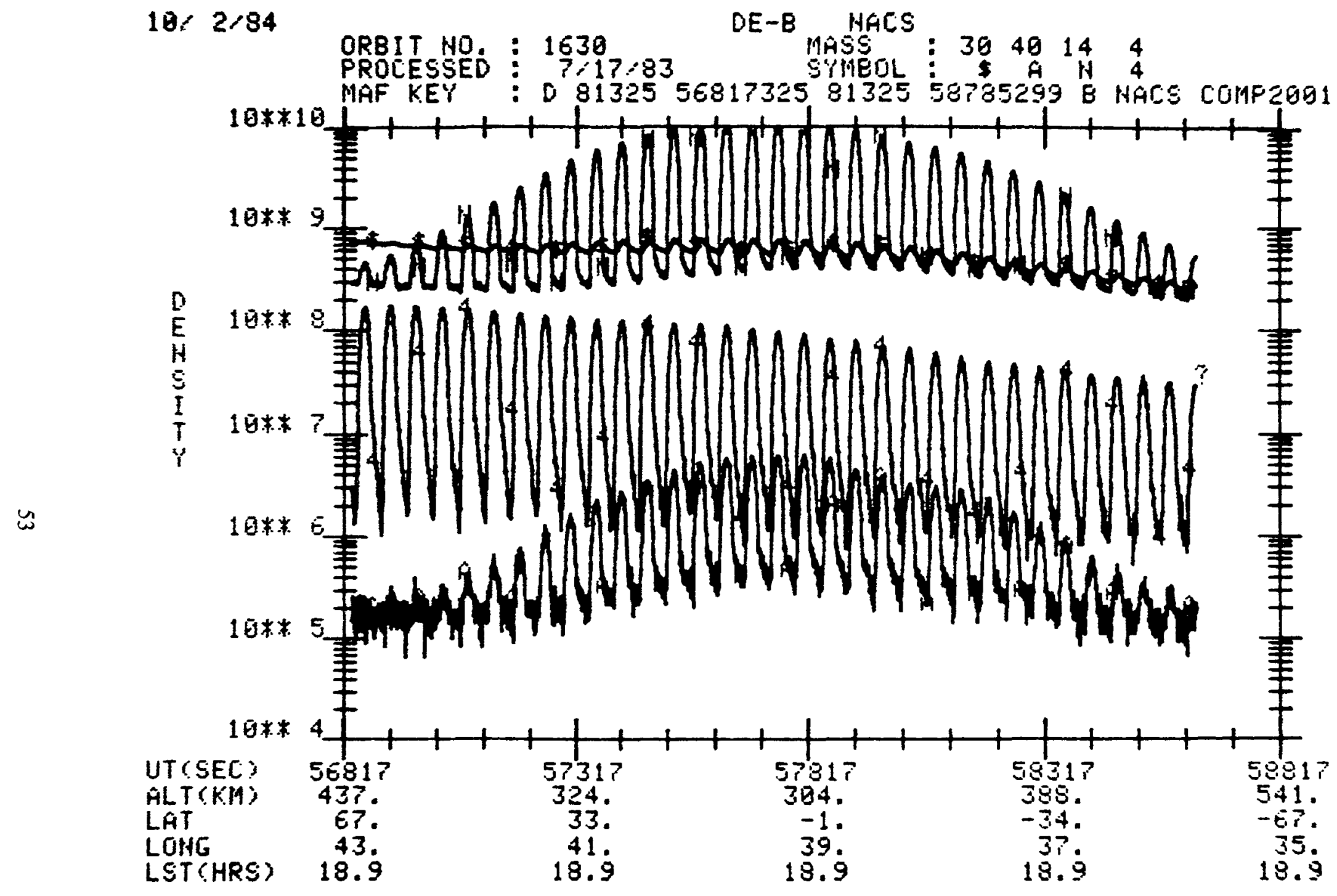

Figure 1. Ion source number densities of $\mathrm{NO}, \mathrm{Ar}, \mathrm{N}_{2}$ and $\mathrm{He}$ measured by the Neutral Atmospheric Composition Spectrometer (NACS) of the Dynamics Explorer-2 satellite on orbit 1630, November 21, 1981. Number densities are plotted on a logarithmic scale as a function of universal time (UT). Also shown on the abscissa are satellite altitude, geographic latitude and longitude, and local solar time. 


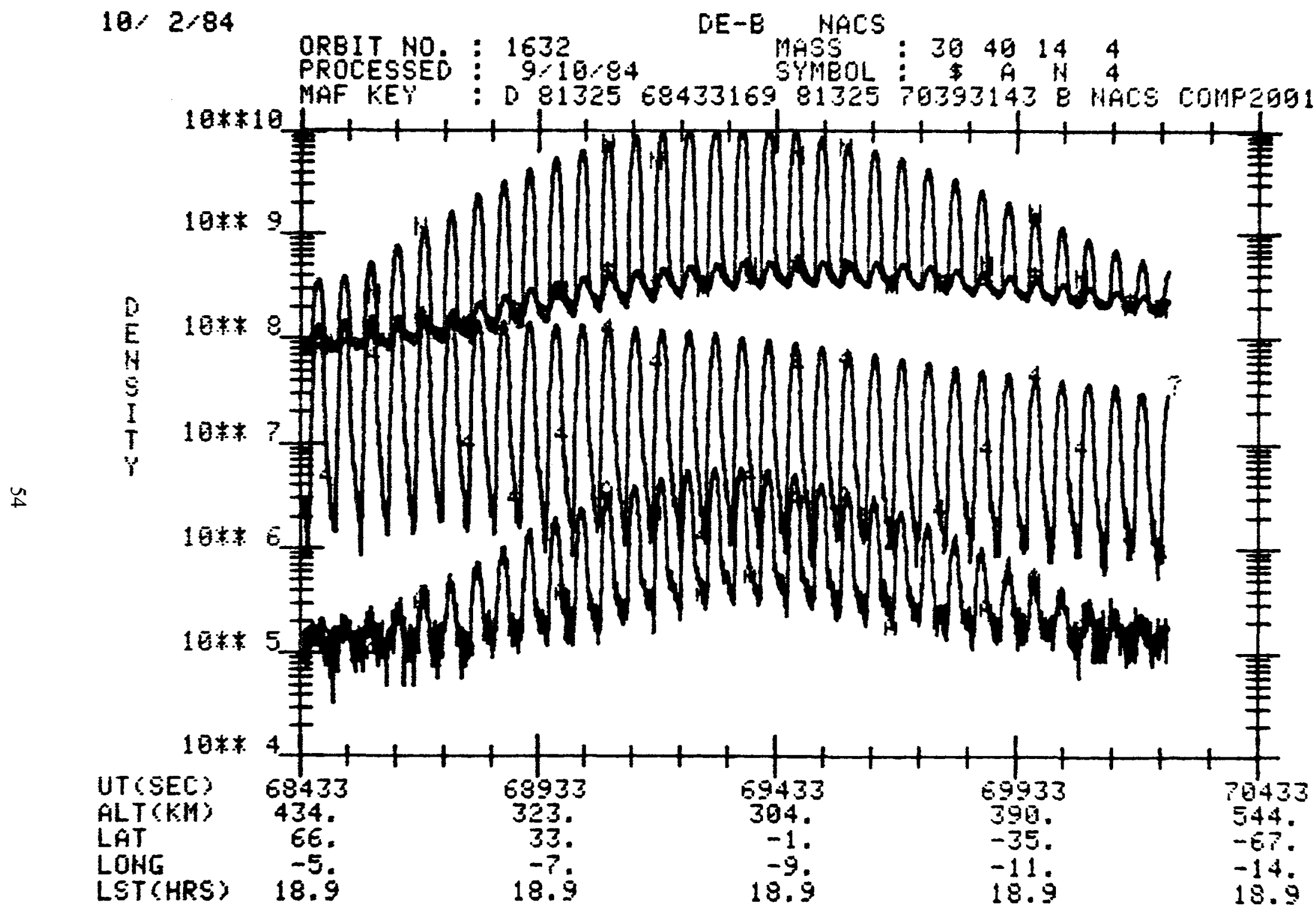

Figure 2. Ion source densities of NO, Ar, $\mathrm{N}_{2}$, and He for orbit 1632 of DE-2, run on November 21, 1981, as in Figure 1. 


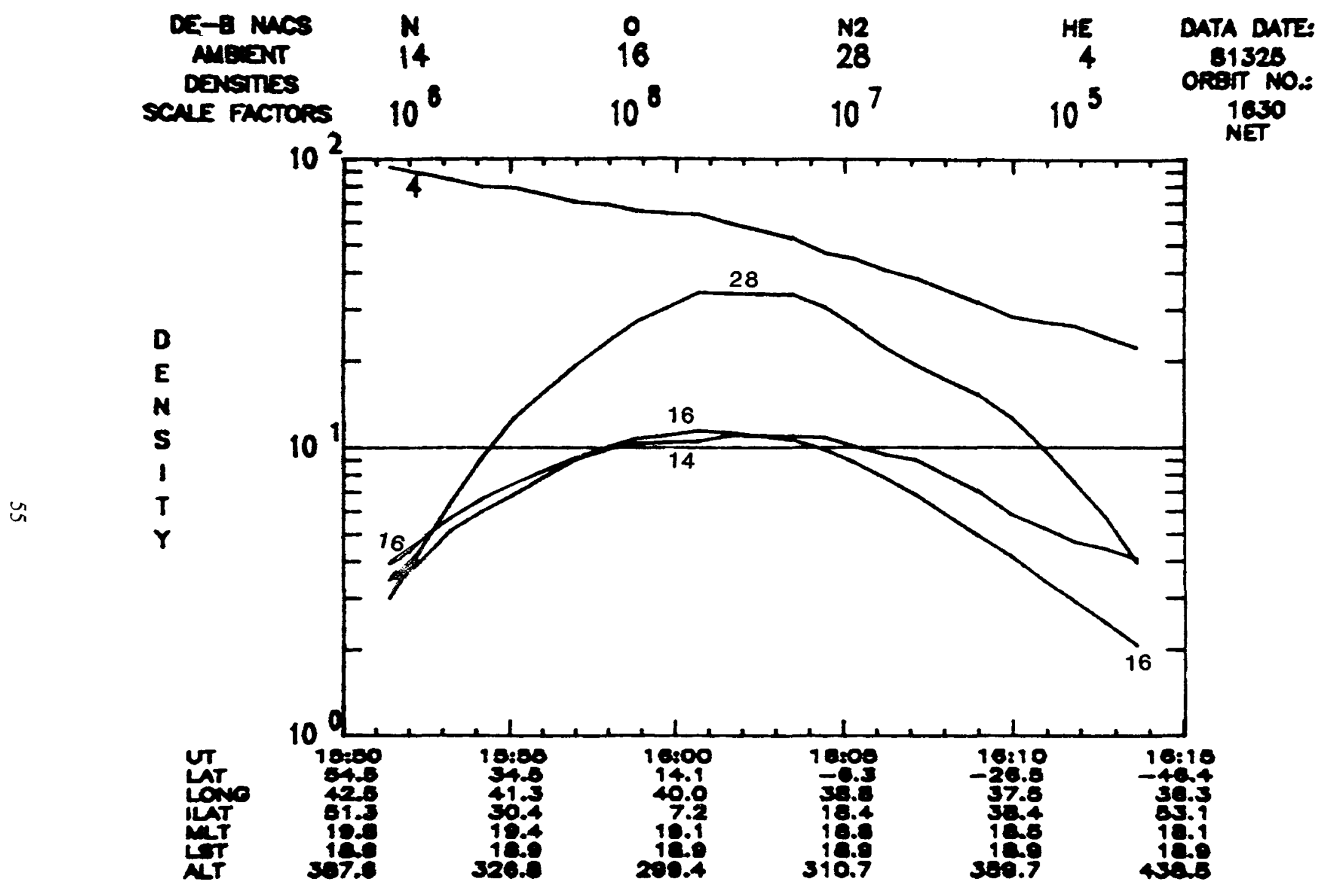

Figure 3. Ambient number densities of $\mathrm{N}, \mathrm{O}, \mathrm{N}_{2}$, and He determined from DE-2 NACS data for orbit 1630, November 21, 1981. Number densities are plotted on a normalized logarithmic scale as a function of universal time. The densities shown in the graph are to be multiplied by the appropriate scale factor shown at the top of the figure to give the correct ambient densities. 


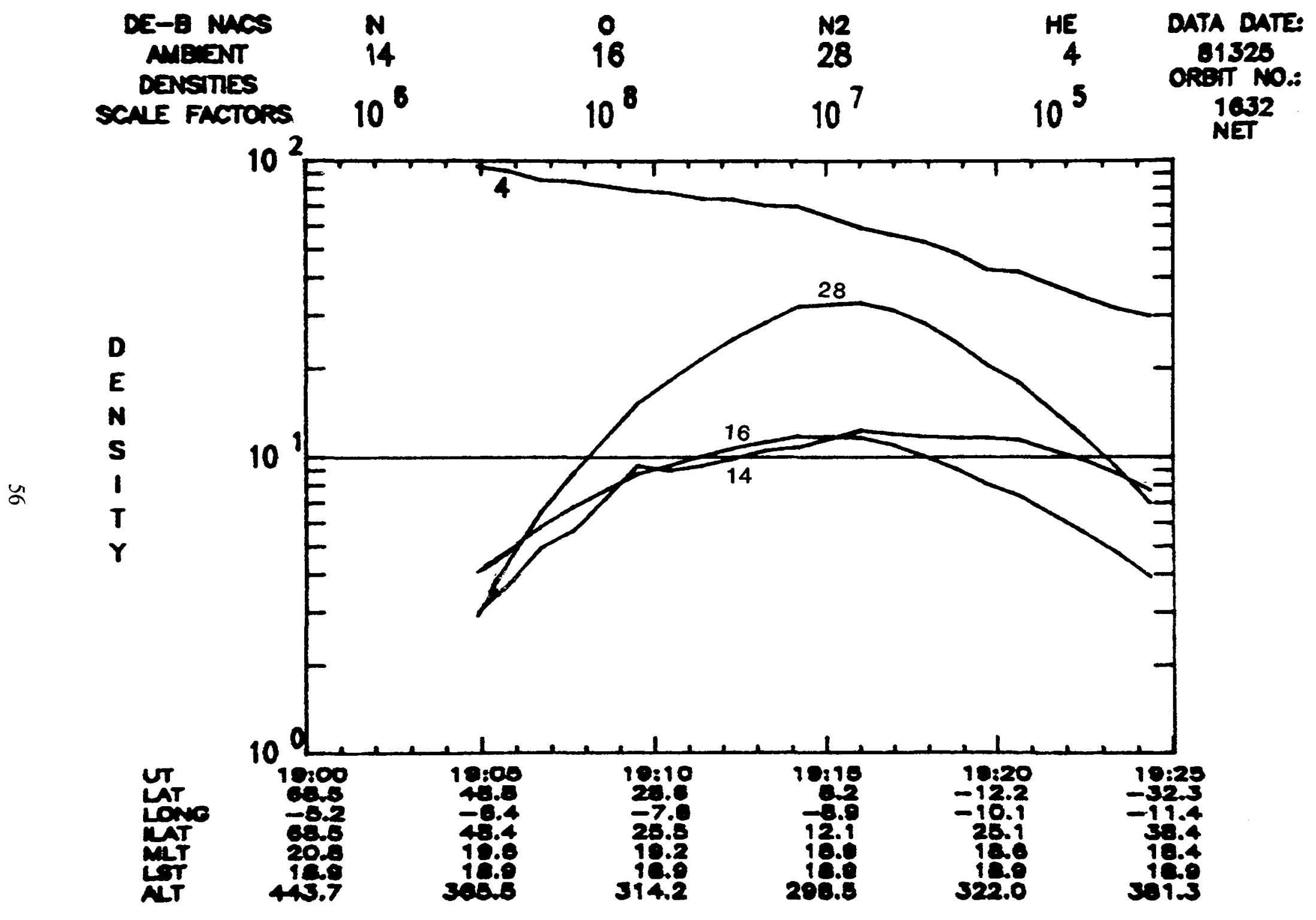

Figure 4. Ambient number densities of $\mathrm{N}, \mathrm{O}, \mathrm{N}_{2}$, and He determined from DE-2 NACS data for orbit 1632, November 21, 1981, as in Figure 3. 


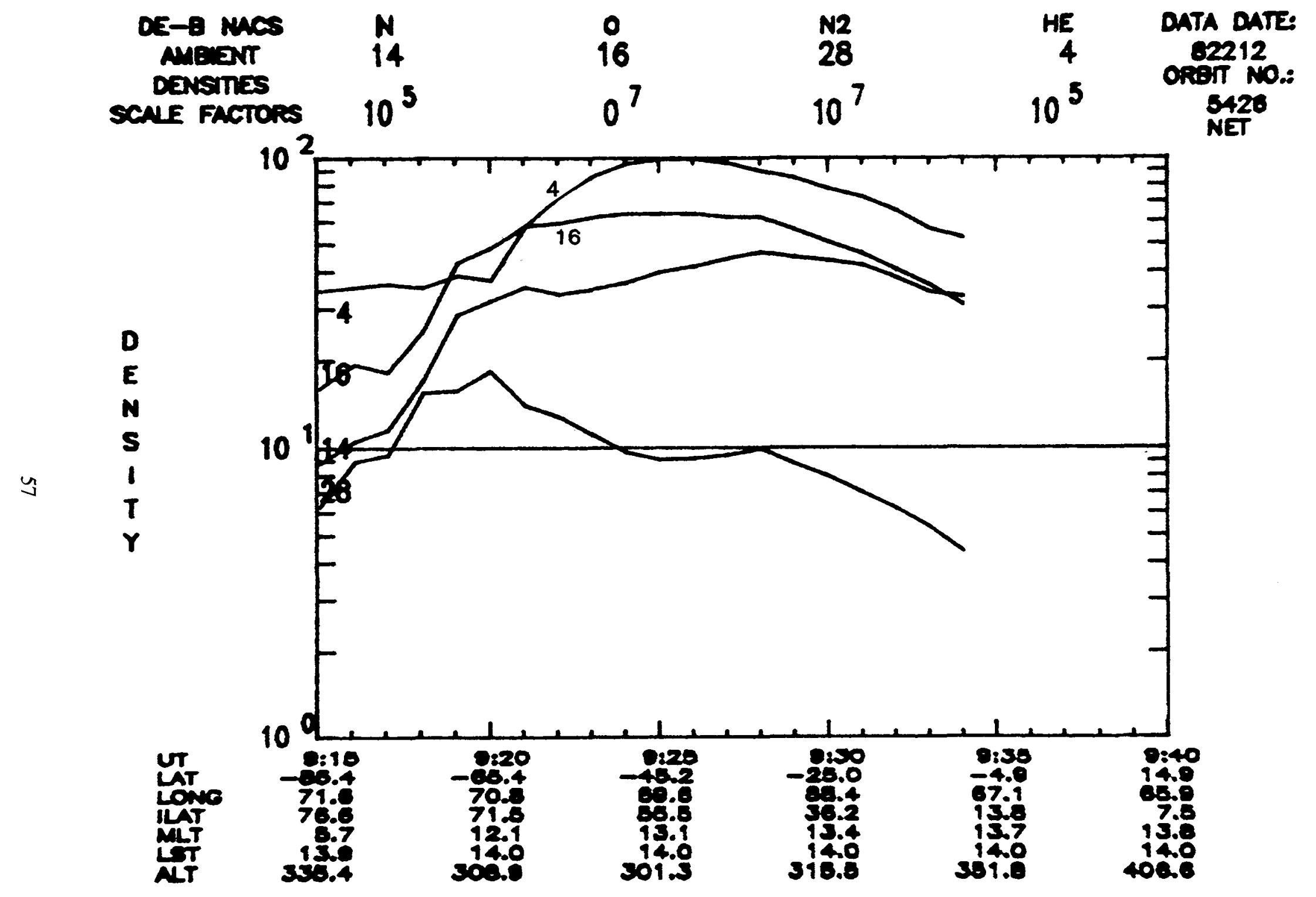

Figure 5. Ambient number densities of $\mathrm{N}, \mathrm{O}, \mathrm{N}_{2}$, and He determined from DE-2 NACS data for orbit 5426, July 31, 1982, and in Figure 3. 


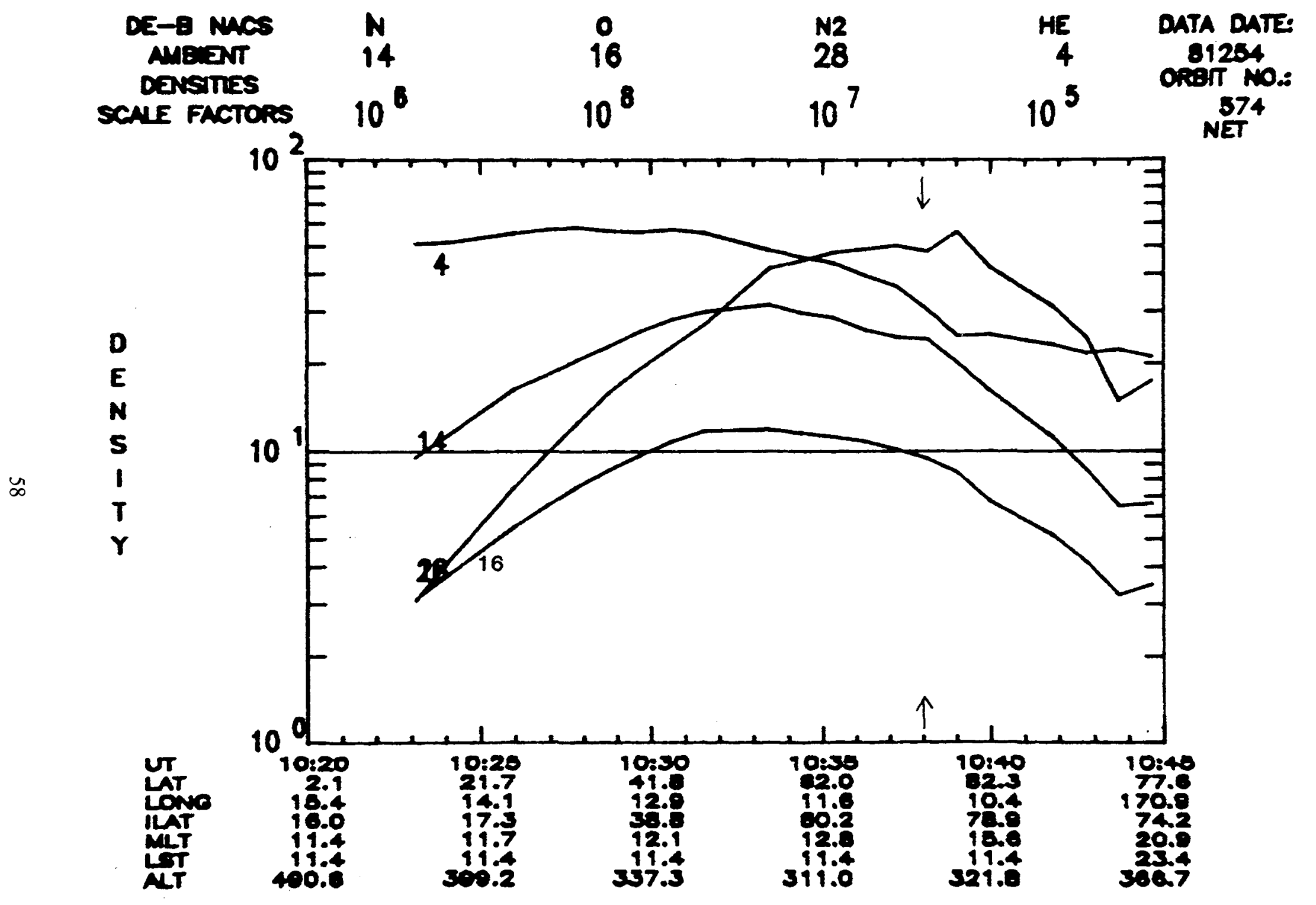

Figure 6. Ambient number densities of $\mathrm{N}, \mathrm{O}, \mathrm{N}_{2}$, and He determined from DE-2 NACS data for orbit 574 , September 11, 1981, as in Figure 3. 


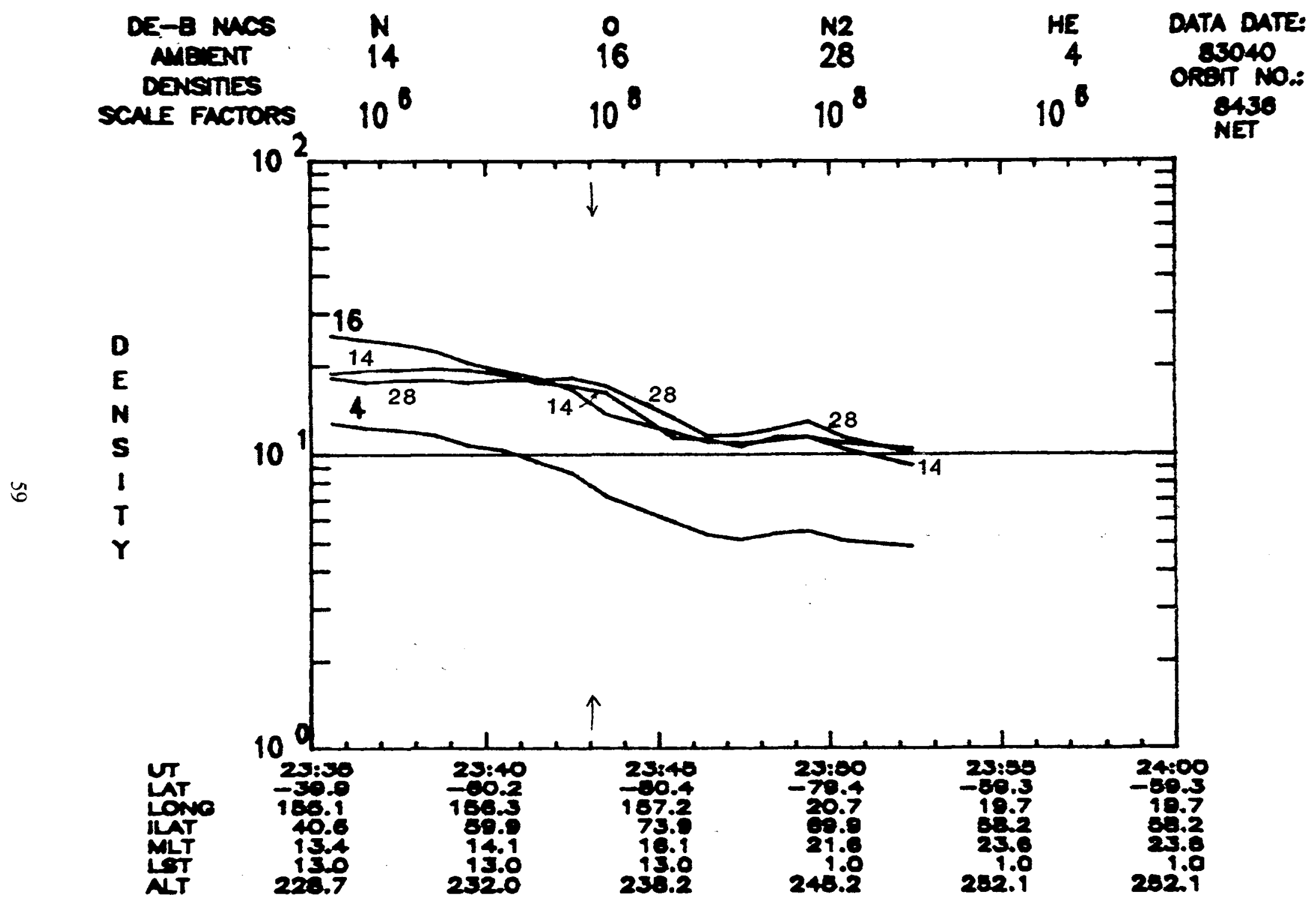

Figure 7. Ambient number densities of $\mathrm{N}, \mathrm{O}, \mathrm{N}_{2}$, and He determined from DE-2 NACS data for orbit 8436, February 9, 1983, as in Figure 3. 


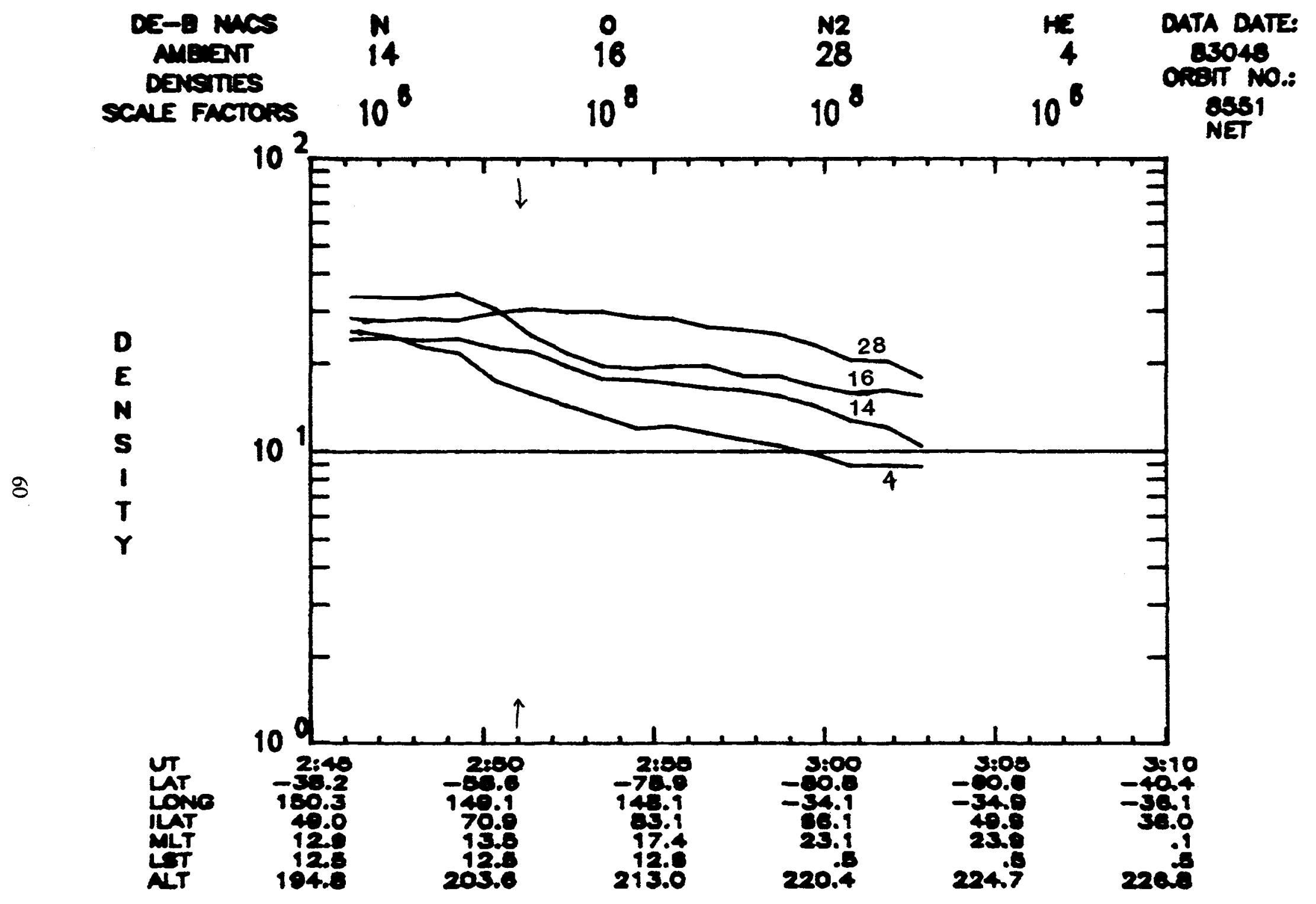

Figure 8. Ambient number densities of $\mathrm{N}, \mathrm{O}, \mathrm{N}_{2}$, and He determined from DE-2 NACS data for orbit 8551, February 17, 1983, as in Figure 3. 


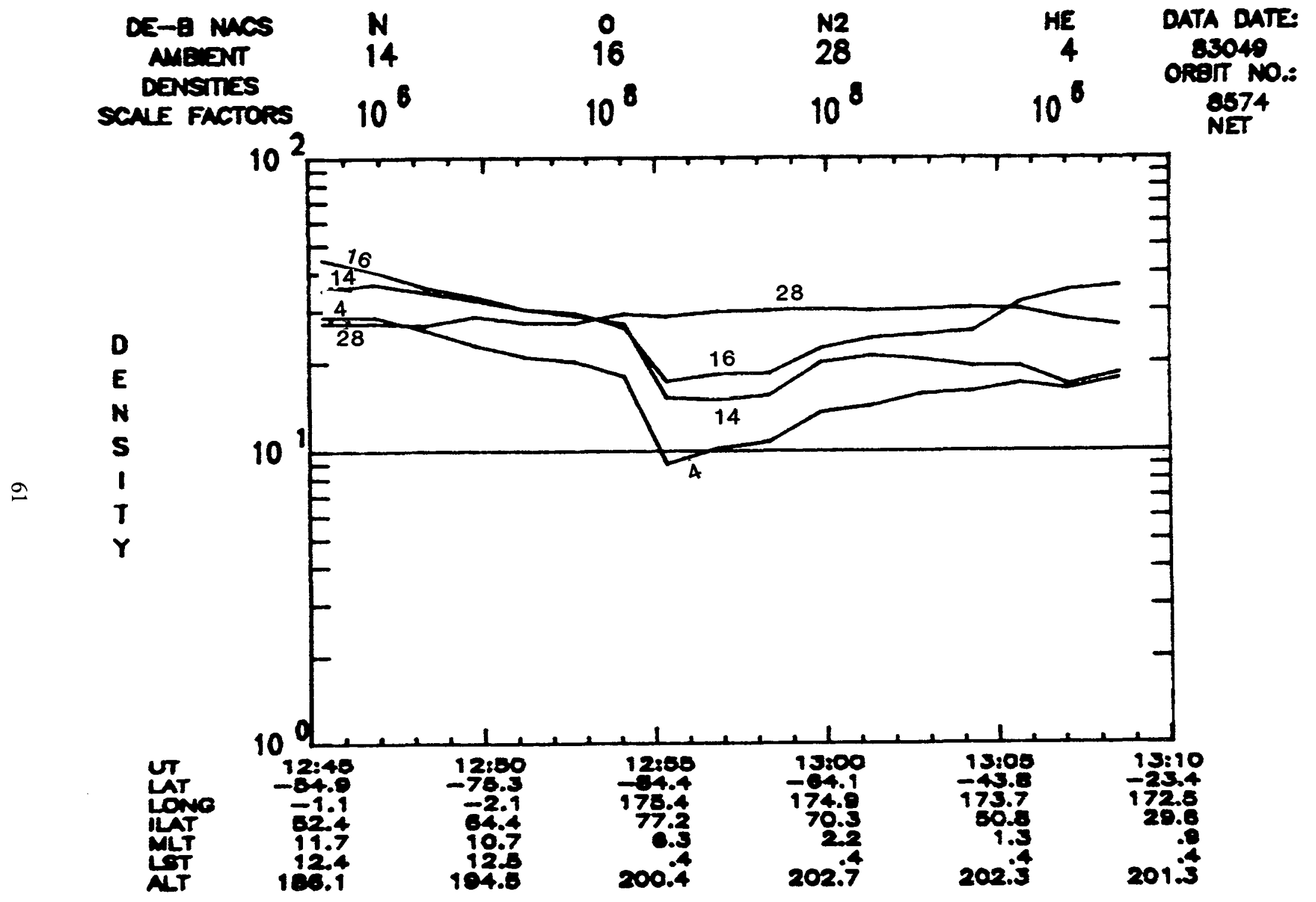

Figure 9. Ambient number densities of $\mathrm{N}, \mathrm{O}, \mathrm{N}_{2}$, and He determined from DE-2 NACS data for orbit 8574, February 18, 1983, as in Figure 3. 